\title{
Comunicação de más notícias pelos médicos no primeiro ano de internato: um estudo exploratório
}

Fátima Leal-Seabra, Manuel J. Costa

Introdução. A compreensão das dificuldades dos médicos no processo de comunicação de más notícias, em particular de médicos recém-diplomados, pode contribuir para orientar o desenvolvimento de formação nessa temática.

Objetivo. Este estudo procurou explorar as perceções de internos recém-licenciados relativamente à sua a preparação para comunicar más notícias e relativamente às características de programas dos curricula de medicina consideradas desejáveis para uma adequada formação.

Sujeitos e métodos. Realizou-se um estudo exploratório de natureza qualitativa com dois grupos focais $(n=6$ e $n=7)$ com internos com menos de um ano de experiência, num hospital em Portugal. As sessões foram gravadas em áudio, transcritas e submetidas a análise temática.

Resultados. Os internos relataram dificuldades e insegurança na transmissão de más notícias, embora considerassem possuir boas competências de comunicação na generalidade. As suas principais dificuldades consistiam em lidar com as emoções e reações do médico e dos pacientes como o choro e o silêncio. A existência de vivências prévias de experiências negativas condicionava a sua segurança neste processo. Estes apontaram como limitações à sua formação pré-graduada nesta área, o ensino precoce e desarticulado nos curricula e a insuficiência de formação prática.

Conclusão. 0 melhoramento da preparação dos jovens internos na comunicação de más notícias deve cuidar os aspetos emocionais do processo. Estes consideram ser fundamental desenvolver programas longitudinais de formação nos curricula dos cursos de medicina, recorrendo a contextos de treino simulados e reais.

Palavras-chave. Competências clínicas. Comunicação clínica. Internato médico. Más notícias. Relação médico-doente. Revelação da verdade.

\section{Breaking bad news by first year residents -an exploratory study}

Introduction. Understanding the difficulties in breaking bad news of doctors recently graduated from medical school is important to guide the development of undergraduate education in this area of patient-physician communication.

Aim. To explore the perceptions of medical graduates at the end of their first year of residency, concerning their present preparation for breaking bad news and the desirable characteristics of effective undergraduate medical curricula in this area.

Subjects and methods. This was a qualitative exploratory study with two focus groups of first year residents $(n=6$ and $n=7)$ of a hospital in Portugal. The focus group sessions were audio-recorded, transcribed and subjected to thematic analysis.

Results. The residents reported difficulties and insecurity in breaking bad news, even though they considered having good communication skills in general. Their main difficulties were to deal with the emotions and reactions of the physician and patient, such as crying and silence. Previous negative experiences conditioned their security in breaking bad news. The main limitations acknowledged in their undergraduate training in this area, were early and disjointed education in curricula and the lack of practical training.

Conclusion. The improvement of medical training in breaking bad news should pay attention to the emotional aspects of the process. Undergraduate medical curricula should be designed longitudinally, involving simulation as well as real contexts.

Key words. Breaking bad news. Clinical communication. Clinical skills. Internship and residency. Physician-patient relations. Truth disclosure.
Faculdade de Medicina; Universidade do Porto; Porto (F. Leal-Seabra). Escola de Ciências da Saúde; Universidade do Minho; Braga, Portugal (M.J. Costa).

Correspondencia: Fátima Leal Seabra. Unidade de Psicologia Médica. Faculdade de Medicina. Universidade do Porto. Alameda Professor Hernâni Monteiro. 4200-319 Porto, Portugal.

E-mail:

fatima.seab@gmail.com

Conflicto de intereses: No declarado.

Competing interests: None declared.

(c) 2015 FEM 


\section{Introdução}

Uma comunicação adequada entre o médico e o paciente produz vários efeitos desejáveis. Relativamente ao paciente favorece a participação e envolvimento na decisão clínica, bem-estar emocional e psicológico, adesão à terapêutica e satisfação global com as consultas/tratamentos [1-3]. Relativamente ao médico, traduz-se em maiores satisfação profissional, capacidade de assimilação das perspetivas do doente nomeadamente as suas crenças, valores, preocupações e preferências para otimização de cuidados médicos, bem como numa maior cooperação e confiança com o doente [1]. Outros efeitos documentados são o reconhecimento da qualidade e eficiência dos cuidados prestados e redução de queixas de más práticas médicas [1].

As competências de comunicação podem ser ensinadas, aprendidas e desenvolvidas de forma estruturada, pelo que existe uma preocupação crescente em introduzi-las nos curricula de formação médica pré- [4] e pós-graduada [5]. O desenvolvimento das competências de comunicação requer treino, supervisão e feedback contínuo, o que recomenda uma articulação e estruturação longitudinal para esses programas [5-7]. Porém, a aprendizagem e desenvolvimento das competências de comunicação em contexto clínico decorre tradicionalmente de forma informal e relativamente pouco estruturada, através da observação e do acompanhamento na prática clínica de outros médicos [6]. A investigação sobre a eficácia de modelos curriculares ou de metodologias de aprendizagem das competências de comunicação clínica não é ainda esclarecedora relativamente a questões cruciais, como por exemplo qual o momento mais indicado para iniciar o seu ensino ou quais os requisitos essenciais de programas longitudinais de formação [4,7]. Um estudo comparativo entre escolas médicas holandesas revelou que esta aprendizagem deverá começar o mais precocemente possível, com formação teórica e prática supervisionada e preferencialmente ao longo de todo o percurso académico [8]. Em Portugal, o ensino das competências de comunicação clínica ao nível pré-graduado desenvolve-se em cada instituição segundo modelos curriculares específicos, cuja eficácia é desconhecida.

A comunicação de más notícias tem impacto relevante sobre quem transmite e recebe a informação $[1,9]$. Efetivamente, transmitir más notícias pode resultar em stress e angústia no doente e no clínico $[10,11]$. As 'más notícias' são definidas como 'situações onde não há um sentimento de esperança, são uma ameaça ao bem-estar físico ou mental, causa- doras de risco de perturbação dos estilos de vida, ou aquelas que conferem poucas escolhas ao doente relativamente à sua vida' [12]. A ubiquidade das más notícias na prática clínica recomenda que todos os clínicos, independentemente da sua experiência ou especialidade, sejam competentes na sua transmissão $[6,13]$. Contudo, embora os jovens médicos se considerem preparados na generalidade em competências de comunicação [14], estes sentem-se menos aptos para transmitir más notícias $[15,16]$. Por conseguinte, é fundamental compreender como as escolas médicas podem formar médicos confiantes e competentes nesta temática. A investigação sobre as perspetivas e a compreensão das experiências de médicos recém-licenciados na transmissão de más notícias, tem sido preterida em favor de publicação de recomendações sobre o processo, a perceção e o impacto em quem recebe as más notícias ou revisões de metodologias de ensino e implicações nas competências dos formandos nesta área [9].

Este estudo exploratório pretendeu explorar e compreender as experiências na comunicação de más notícias de médicos com menos de um ano de experiência profissional em Portugal: os designados 'internos do ano comum'. Optou-se por entrevistar grupos focais, pois este método faculta a recolha duma vasta gama de perceções dos internos, já que a discussão em grupo leva os participantes a refletir com maior profundidade sobre as suas perceções individuais [17]. Mais especificamente, os objetivos do estudo foram avaliar as perceções dos internos de ano comum relativamente à sua preparação para comunicar más notícias, identificar as suas principais dificuldades e nos relatos das suas experiências os contributos da sua formação pré-graduada na comunicação clínica com especial relevo na transmissão das más notícias. Procurou-se ainda caracterizar as suas experiências formativas prévias, tendo em consideração que estas condicionarão as perceções recolhidas.

\section{Sujeitos e métodos}

\section{Participantes e contexto do estudo}

O contexto deste estudo foi o de um hospital em Portugal e os participantes foram médicos internos de 'ano comum' (IAC's). Em Portugal, o 'ano comum' é o primeiro período de formação médica especializada, teórica e prática, com o objetivo de habilitar o médico ao exercício tecnicamente diferenciado numa especialidade médica [18]. Este tem início após conclusão da formação pré-graduada -o 
Mestrado Integrado em Medicina-, com a duração em regra de seis anos. Todos os IACs cumprem o mesmo programa de formação obrigatório com um ano de duração, que concluem imediatamente antes de iniciar a sua formação numa especialidade médica ou cirúrgica [18].

Participaram treze internos do ano comum, que iniciaram a sua atividade profissional em 2013, no referido hospital. Foi utilizada uma amostra intencional [19], em que houve a seleção de sujeitos com maior potencial informativo, após preenchimento dum questionário, relativo à idade, sexo, ano de início e de término do curso de medicina, faculdade que frequentou, média de curso, classificação na prova de exame nacional para acesso à especialidade, especialidade que desejava frequentar e disponibilidade para participar no estudo. No estudo participaram 13 IAC's (10 do sexo feminino, 3 do sexo masculino), com idade média de 25 anos e eram oriundos de todas as faculdades de medicina portuguesas. Estes tinham média final de 15,9 valores numa escala de 0 a 20 valores e com variância entre 15,2 e 17 valores. A classificação final média na prova nacional para acesso de especialidade era de 76,6 pontos numa escala de 0 a 100 e com variação entre 56 e 93 pontos. Destes 8 desejavam ingressar numa especialidade médica, 3 numa cirúrgica, 1 numa médico-cirúrgica e 1 numa de diagnóstico. Os IAC's foram recrutados pessoalmente, telefonicamente ou por intermédio de e-mail.

\section{Método de recolha de informação}

Os grupos focais foram escolhidos como o método para este estudo, pela sua eficácia para captar as perceções comuns do grupo alvo. O estudo foi conduzido com a autorização da Direção do Internato do hospital e todos os participantes assinaram um termo de consentimento informado, obtido no início de cada entrevista. A participação foi voluntária, tendo sido garantido o anonimato e a confidencialidade sobre as declarações recolhidas. Foram conduzidas discussões semiestruturadas de dois grupos com sete e seis participantes $(n=7$ ou $n=6)$, cada. Estas tiveram duração de $3 \mathrm{~h}$ e realizaram-se em ambiente privado numa sala do hospital, com base num guião.

O guião foi elaborado pelos dois autores, com base nos resultados duma pesquisa bibliográfica sobre a comunicação de más notícias. Realizou-se um teste piloto através da simulação de uma entrevista com dois internos do ano comum, sob gravação áudio, tendo sido recolhidas as perspetivas e sugestões dos participantes relativamente ao tipo de ques-
Tabela I. Guião da entrevista.

Foquem-se no dia-a-dia a vossa prática clínica. Esqueçam as vossas inseguranças e coloquem-se nas situações em que estão perante o doente

Como avaliam a vossa capacidade de comunicar com o doente?

Sentem-se à vontade a falar com o doente? Se não, porquê?

Que tipo de doente/situações o deixam pouco à vontade?

Qual a vossa perceção sobre o conforto do doente quando conversa convosco?

Indique os aspetos da comunicação em que estejam mais à vontade?

Imaginem que têm de transmitir a um doente uma notícia que vos parece ser desagradável para o doente Já estiveram nessa situação?

Quando foi a primeira vez? Quantas vezes tiveram do fazer? Foi sozinho? (se nunca o fizeram, reportem-se às vossas experiências passadas, nomeadamente durante a formação médica)

Alguma vez presenciaram uma situação dessas?

Quantas vezes presenciaram?

Quando foi a primeira vez que presenciaram?

Descreva o que acharam dos colegas que viram a transmitir a notícia desagradável

Imaginem que têm a responsabilidade de transmitir más notícias a um doente

Como é que dariam essa notícia? Como é que começariam?

Que cuidados especiais teriam nessa situação?

Que dificuldades poderiam surgir? O fariam para as ultrapassar?

Quando a má notícia é transmitida, esta causa reações/emoções no clínico e no doente. Reportem-se às vossas experiências prévias ou caso nunca tenham estado presentes imaginem-se na situação

Como se sentiram antes da transmissão dessa notícia? E durante? E depois?

Que reações/emoções mais vos incomoda?

Em relação ao que aprenderam sobre comunicação com os doentes na universidade Consideram que esta vos preparou para a vossa atividade profissional? Em particular para a transmissão de más notícias?

Em relação ao treino da comunicação na vossa universidade. 0 que deveria mudar?

Que alterações fariam se pudessem? E no pós-graduado/internato médico?

tões, conteúdos abordados, clareza da linguagem e duração da entrevista, no final da mesma. O guião foi reelaborado de acordo com as sugestões indicadas pelos internos e com a análise dos investigadores sobre $\mathrm{o}$ assunto.

O guião final consistia num conjunto de cinco temas introdutórios com respetivas perguntas, apresentados na tabela I. Todas as questões foram utilizadas durante a entrevista.

\section{Análise}

Os dados recolhidos foram submetidos a uma análise qualitativa, tendo sido considerados os princípios encontrados em Grounded-Theory [20-22]. A open-coding bem como a axial-coding [19] foram utilizados na concretização desta análise. As transcrições foram codificadas de forma independente por dois investigadores, usando uma análise linha- 
Tabela II. Fatores que podem influenciar a capacidade de comunicação com os doentes

\begin{tabular}{|c|c|}
\hline \multirow{12}{*}{$\begin{array}{l}\text { Relacionados } \\
\text { com o médico }\end{array}$} & Inseguranças pessoais \\
\hline & Incapacidade de demonstrar confiança \\
\hline & Idade do clínico \\
\hline & Comentários depreciativos pelos doentes \\
\hline & $\begin{array}{l}\text { Receio de insuficiência de conhecimentos específicos } \\
\text { relativos a patologias e planos terapêuticos }\end{array}$ \\
\hline & Nível de conhecimento prévio do doente \\
\hline & Inexistência de seguimento posterior pelo médico \\
\hline & Incapacidade de responder às perguntas colocadas pelo doente \\
\hline & Incerteza de dominar uma linguagem compreensível por parte do doente e do clínico \\
\hline & $\begin{array}{l}\text { Dúvidas sobre a capacidade de compreender em tempo } \\
\text { útil as expectativas da parte do doente e sua família }\end{array}$ \\
\hline & Ter que comunicar informação 'sensível', como más notícias \\
\hline & Apreensão quanto às emoções que pode suscitar no doente e em si próprio \\
\hline \multirow{8}{*}{$\begin{array}{l}\text { Relacionados } \\
\text { com o doente }\end{array}$} & $\begin{array}{l}\text { O tipo de doente: crianças, doentes oncológicos, afásicos, demenciados, } \\
\text { agressivos, em fase terminal da doença, apelativos e com distúrbios psiquiátricos }\end{array}$ \\
\hline & Pouca capacidade de compreensão e/ou baixo ou elevado nível de literacia \\
\hline & Idade semelhante à do clínico \\
\hline & Recusa em conhecer informações sobre o seu estado clínico \\
\hline & Ausência de conhecimento da realidade da sua situação clínica \\
\hline & Ser conhecido ou familiar de outro profissional de saúde \\
\hline & Ser estrangeiro ou pertencer a outras culturas/etnias \\
\hline & Familiares do doente \\
\hline \multirow{6}{*}{$\begin{array}{l}\text { Relacionados } \\
\text { com o contexto }\end{array}$} & Ambiente em que decorre o processo de comunicação \\
\hline & Contexto específico do serviço de urgência \\
\hline & A inexistência de privacidade \\
\hline & Transmissão de informação a familiares desconhecendo se seria esse o desejo do doente \\
\hline & $\begin{array}{l}\text { Doente ser tratado como um objeto para execução } \\
\text { de técnicas, de observação e de ensino médico }\end{array}$ \\
\hline & $\begin{array}{l}\text { Necessidade de agir de forma diferente das suas convicções ditada por } \\
\text { exigências do serviço, por exemplo o interno ser incitado a comunicar informação } \\
\text { clínica por telefone, quando este considera o procedimento inapropriado }\end{array}$ \\
\hline
\end{tabular}

a-linha para caracterizar os códigos presentes no texto. Os investigadores reuniram-se e discutiram a codificação até chegarem a um consenso quanto aos códigos finais. Analisaram-se pontos em comum entre os vários comentários dos participantes para discernir pontos-chave e os códigos foram agrupados. Este processo indutivo garantiu que as conclusões fossem fundamentadas nos dados coletados. Os temas gerados a partir da análise dos dois grupos foram comparados entre si e sintetizados conjuntamente.

\section{Resultados}

\section{Perceções sobre competências genéricas de comunicação}

Os participantes foram unânimes em considerar que as boas capacidades de comunicação tinham um impacto positivo sobre os doentes. Onze internos consideravam que possuíam uma boa capacidade geral de comunicação clínica, embora a sua segurança fosse suscetível a vários fatores detalhados na tabela II. Os internos referiram vários aspetos do processo de comunicação clínica em que sentiam maior à vontade, nomeadamente a capacidade de recolher a história clínica, de ajudar o doente a perceber sobre o que se passava com ele, informar ao longo de um procedimento ou avaliação médica o doente e familiares, transmitindo informações seguras. Foi considerado que a adoção destes cuidados ao longo do processo de comunicação clínica era apreciada pelos doentes, fortalecia a relação médico-doente e que fazia com que os internos se sentissem mais seguros na comunicação clínica.

\section{As experiências dos internos com a comunicação de más notícias}

Constatou-se que todos os participantes tinham presenciado a comunicação de más notícias (uma a três más situações). Nove participantes tinham feito a comunicação e sem supervisão todos, com exceção de um. As más notícias mais comuns reportavam-se a diagnósticos, particularmente os associados a doenças oncológicas. As menos comuns incluíam a comunicação da morte do doente ao familiar, o internamento ou a necessidade inesperada duma consulta de determinada.

Relativamente às vivências de transmissão da má notícia por outros médicos, estas eram divergentes. Foram referidos casos em que o médico conseguiu ser agradável, conseguiu 'dar a notícia de uma maneira engraçada, mas que não tinha graça, conseguia sempre brincar um bocadinho', teve cuidado na transmissão desta, estava à vontade e era huma- 
no. Porém, houve referência a situações de insensibilidade e de frieza do clinico ('o seu marido vai morrer em seis meses'), transmissão de informação de forma leviana ('de repente disse ao doente que já tinha sido amputado [...] até meio da perna que agora ia ter de amputar até à base da coxa [...] é mais perna menos perna'), sem explicar ao doente, sem facultar pormenores, sem esclarecer as dúvidas ou estabelecer um plano futuro. Outros aspetos que estiveram associados a má experiência deviamse à manifestação de um juízo de valor sobre os comportamentos do doente ('vai morrer porque não quis saber, não quis cuidar'); à atitude paternalista do médico ('[...]antes de começar a falar a notícia já está a dar palmadinhas nas costas[...]') e deste ocultar a real informação sobre o verdadeiro estado de saúde ('[...] o médico tinha dito que ele estava bom que podia ir para casa, que estava como novo, que tinha posto só a prótese [...] depois fui ver ao processo e ele tinha tratamento paliativo e tinhamlhe dito que ele estava bom que estava curado').

\section{Más notícias: perspetivas e dificuldades}

Relativamente à comunicação de más notícias, emergiu a existência de insegurança nos participantes. Os internos consideravam que a forma de comunicar más notícias era variável de doente para doente e que era fundamental seguir vários pilares da comunicação clínica. Entre estes referiram a preparação prévia do médico, a adequação do ambiente ('um pouco mais recatado, um bocadinho afastado da correria dos corredores'), privado e a meia-luz pois 'ajuda a pessoa a ir interiorizando' e à compreensão do doente (o que sabe, o que deseja saber/as expectativas, a rede de apoios - porque 'os doentes a partir do momento em que ouvem - tenho um cancro - não querem ouvir mais nada e é importante estar lá alguém que oiça o resto e que depois possa, dizer ao doente'). Denotaram sensibilidade, ao manifestar a necessidade de dar um sinal de que o médico era detentor de informação importante para o doente e prepará-lo de que esta não seria agradável, usando a comunicação não-verbal ('tentar dar logo a perceber à pessoa pela [...] postura e pelo [...] tom de voz [...] que a notícia não é boa') e verbal ('preciso de falar consigo um assunto mais delicado, uma situação [...] que poderá a incomodar'), à utilização de linguagem direta e adequada ao nível de compreensão do doente sobre o significado e as implicações da informação para a sua vida, e à importância de dar tempo ao doente para este ou os seus familiares falarem, colocarem dúvidas. Outro aspeto fundamental passava pela obser-
Tabela III. Más notícias: as dificuldades.

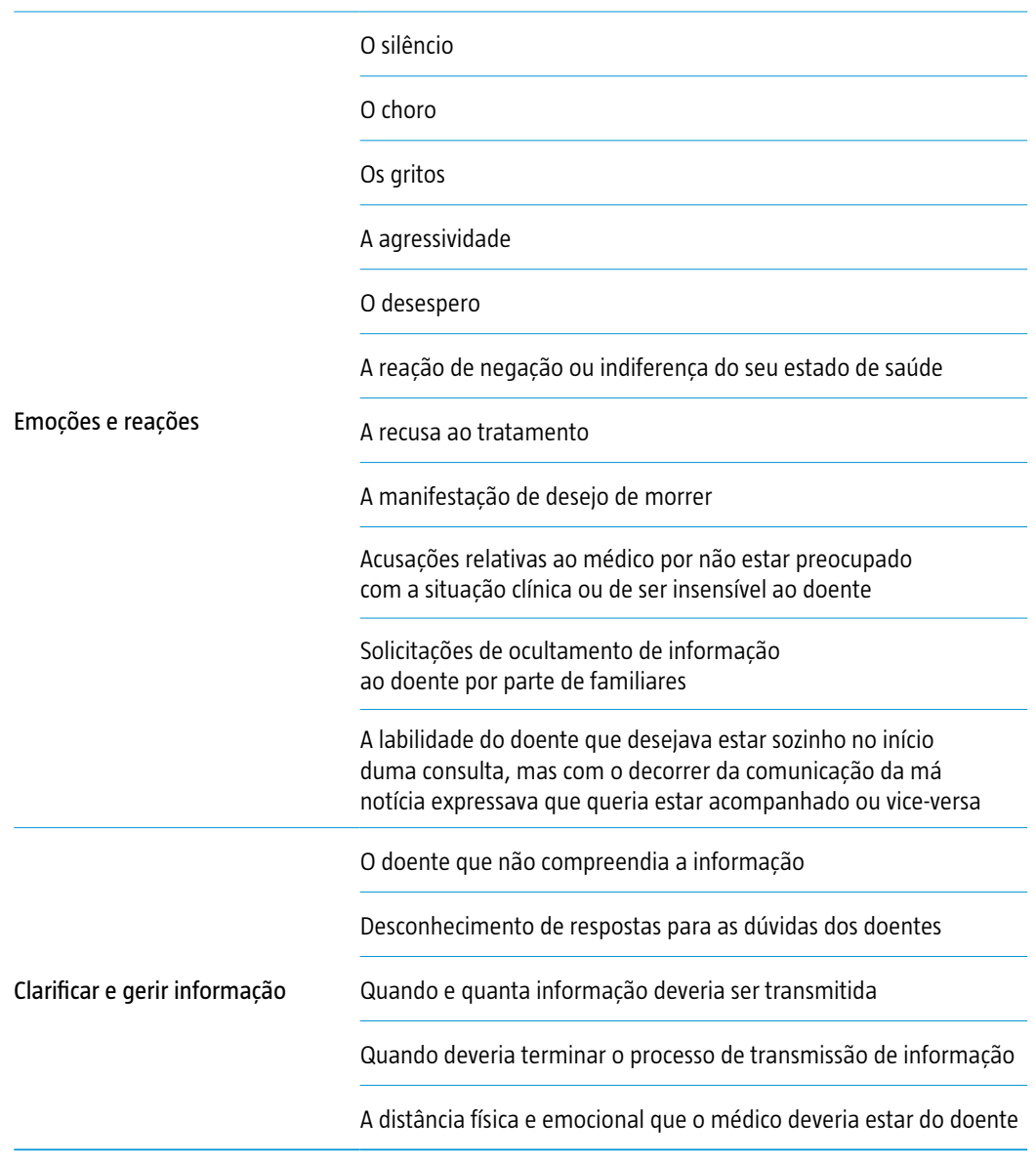

vação das reações e emoções dos doentes, com especial atenção para os silêncios e o choro. Na transmissão da má notícia o médico deveria ainda estabelecer um plano, o seguimento e demonstrar disponibilidade 'para as pessoas posteriormente pensarem e reunirem as suas dúvidas [...] e saberem que depois podem perguntar'.

A dificuldade mais enfatizada prendeu-se com o lidar com as emoções/reações do doente. Os participantes ficavam desconfortáveis e não sabiam como lidar com o choro ('chorar ou gritar ou [...] acho que ia ser uma dificuldade para tentar acalmar a pessoa [...]') e o silêncio dos doentes ('a pessoa transmite a notícia e o doente depois fica em silêncio [...] fica pensativo e depois também não diz nada, uma pessoa fica sem saber o que fazer') (Tabela III). Outras dificuldades relatadas relacionavamse com a clarificação e gestão da informação transmitida ('[...] à partida a não compreensão do que está a ser comunicado é uma dificuldade muito grande 
[...]', ‘[...] depois também as dúvidas que podem surgir, para as quais se calhar nós até deveríamos saber a resposta [...]', 'uma outra grande dificuldade é o relógio, desta notícia, quando é que chega? Quando é que podemos... Quanta mais informação é necessária?') (Tabela III), e 'chegar a casa e desligar' sobre o que se passou durante e após a comunicação.

\section{Más notícias: emoções e reações dos médicos}

Os participantes perspetivaram as suas emoções perante uma situação de comunicar más notícias recordada ou imaginada em três momentos distintos: antes, durante e depois da comunicação da má notícia. As emoções/reações descritas antes da transmissão da má notícia eram a ansiedade e o nervosismo atribuído ao efeito que esta podia ter no doente e família, desconhecendo-se as reações e emoções que pode gerar. Outras reações e sensações dos médicos antes da transmissão eram a insegurança também atribuída ao desconhecimento da própria reação e da do doente, a impotência perante a incapacidade de controlar o desenlace da situação, a tristeza 'se for um doente que a pessoa já segue há bastante tempo' e ainda a compaixão sobre o atual estado de saúde do doente.

No que concerne aos momentos da transmissão das más notícias, os internos indicaram que a ansiedade e o nervosismo, bem como as de desconforto, 'sentir-se a mais' decorrente do desconhecimento sobre que lugar ocupar ou o que dizer ou fazer, perante um doente a exteriorizar as suas emoções.

No final da transmissão das más notícias, dependendo do tipo de má notícia transmitida e da reação do doente, os clínicos poder-se-iam sentir aliviados. Revelaram ainda deceção perante o modo como comunicaram a má notícia, considerando muitas vezes que poderiam ter utilizado uma outra abordagem. Manifestaram que na maioria das vezes não disseram tudo aquilo quanto desejavam; que se sentiam abalados com as reações do doente ou dos familiares, frustrados 'se as coisas correrem mal' e outras vezes contagiados com as emoções manifestadas pelo doente naquele momento.

\section{Experiências formativas na comunicação clínica com especial relevo na transmissão das más notícias}

Todos exceto um interno consideraram insuficiente a preparação proporcionada pela sua formação prégraduada em comunicação clínica. A maioria dos internos referiu-se à sua formação como demasiado teórica e distante da prática médica, advogando o aumento de formação prática nos curricula. Consi- deraram que estas temáticas deveriam ainda ser abordadas longitudinalmente, sobretudo após o formando ter algum contacto prévio com os doentes e ao longo de todos os anos clínicos ('[...] acho que no segundo ano se calhar é um bocadinho cedo abordarmos este tema porque não sabermos grande coisa de patologias, do que é que é uma má notícia mais grave ou menos grave [...], [...] essa competência teria sido importante, se tivesse sido repetida ou relembrada nos anos clínicos em que nós [...] já tínhamos estado em contacto com doentes').

No que concerne às alterações a introduzir no ensino pré-graduado, consideraram que a comunicação clínica deveria ser contemplada na avaliação das aprendizagens em articulação com o conhecimento de diagnósticos ou a definição de um plano de seguimento do doente. Abordaram a importância de haver uma lista de aptidões básicas fundamentais a desenvolver ao longo de toda a formação médica, e que estas fossem constantemente observadas e avaliadas na recolha das histórias clínicas.

Quanto à formação pós-graduada recomendavam que existisse formação contínua em comunicação clínica, particularmente na área das más notícias. Estes sentiam que os serviços não consideravam a comunicação clínica como uma competência fundamental, pelo que propuseram a necessidade de envolver os colégios de especialidade, os serviços clínicos e os hospitais no fomento da formação nesta área. Estes admitiam que a formação só seria aplicada em massa se houvesse uma componente de avaliação e acreditação dos serviços ou dos hospitais nesta área ('sem ser por imposição externa não vejo que isso possa ser aplicado em massa'), bem como a valorização curricular dos profissionais. Sugeriram várias abordagens para melhorar a formação neste tema: a observação de médicos com formação prévia nesta área a comunicarem más notícias, o treino destas competências com doentes reais, formação contínua de especialistas e inclusão destas competências nos exames finais de especialidade.

\section{Discussão}

Este estudo oferece uma visão qualitativa detalhada sobre as perspetivas de jovens médicos perante a comunicação de más notícias. Os resultados sugerem que os internos do ano comum participantes apreciam a importância de serem e de se sentirem competentes na comunicação com os pacientes em particular na comunicação de más notícias. Adicionalmente, o estudo demonstra que a existência de vivências negativas de comunicação más notícias 
pode condicionar a sua confiança. As conclusões que emergiram das impressões e vivências dos internos, sugerem que a formação pré-graduada em comunicação de más notícias deve ser mais estruturada e focar com particular atenção a gestão das emoções. Os desafios considerados muito relevantes para melhorar a formação sobre comunicação de más notícias foram a estruturação longitudinal dessa formação, o privilegiar da prática da comunicação em contextos de consulta sobre a formação teórica em contexto académico e a inclusão da temática nos programas de formação dos internos. Os desafios identificados no contexto português são, na sua generalidade, consonantes com os desafios identificados internacionalmente $[7,9]$.

Perante a comunicação de más notícias, os jovens médicos portugueses revelaram ansiedade $\mathrm{e}$ insegurança, à semelhança de residentes doutros países $[10,11,15,23]$. Estas foram essencialmente atribuídas a dois tipos de motivos, um relacionado com a orientação e os orientadores clínicos, e outro mais centrado em insuficiências da formação prégraduada neste âmbito. As dificuldades relativas à supervisão clínica são comuns internacionalmente $[24,25]$ e as vivências de situações de role-models inadequados na vertente comunicacional são um dos elementos negativos do designado 'curriculum escondido' da formação médica [26]. Relativamente à formação pré-graduada, o aspeto crucial identificado foi a dissociação generalizada entre os modelos teóricos aprendidos relativamente à comunicação clínica e as reais necessidades comunicacionais da prática clínica. Os jovens médicos revelaram dificuldades de lidar com fatores relativos ao contexto físico -por exemplo a (in) existência de privacidade-, ao tipo de doente e ao tipo de notícia a facultar ao doente ou familiares. As questões inerentes ao desfasamento entre programas formativos generalistas e necessidades reais específicas tais como singularidades nas características de doentes é uma dificuldade apontada na literatura internacional [27]. As dificuldades identificadas neste estudo são também apontadas por médicos de diferentes especialidades dos Estados Unidos da América [9]. Os internos americanos descrevem seis fatores que podem dificultar o processo de comunicação clínica, com destaque os associados ao médico, ao doente, à relação entre estes, ao contexto/instituição, à própria doença e a erros médicos [9], que merecem ser estudados e contemplados nos planos de formação médica [19]. Outras dificuldades comuns aos internos portugueses e que são consideradas como barreiras à comunicação clínica são uma auto-perceção de conhecimento insuficiente, incapacidade para res- ponder às dúvidas/perguntas, e para expressar reações e emoções [28]. Neste estudo exploratório, não foram identificadas dificuldades apontadas noutros estudos como o medo pessoal de estar doente ou de morrer bem como a ausência de tempo [29] e as múltiplas burocracias a desempenhar pelo clínico [28].

Um achado de crucial importância que emergiu deste estudo é o desafio de gerir as emoções dos médicos e dos doentes na transmissão de más notícias. Os internos expressaram o seu receio de não conseguirem lidar/controlar as emoções ou reações que os doentes ou as famílias pudessem manifestar perante uma má notícia, apesar de estarem cientes das etapas associadas ao processo de comunicação e de reconhecerem pilares fundamentais para a comunicação de más notícias enumerados em vários modelos/protocolos, nomeadamente no protocolo de SPIKES [30,31]. Eram perturbados por reações dos doentes como o choro, os silêncios, a agressividade, ou a culpabilização do clínico. Estas são descritas como promotoras de medo e stress acrescido no clínico [32], bem como sensação de culpabilização pelo estado de saúde do doente, insegurança e desejo de evitar transmitir a má notícia [32]. Deste modo, tal como verificado num estudo holandês, as emoções do clínico também podem contribuir positiva e negativamente no processo de comunicação [27].

Os participantes sentiam-se confortáveis nos aspetos gerais da comunicação com os pacientes, tal como os médicos que participaram num estudo baseado em questionários no Reino Unido [14,15,33]. Perante as dificuldades na comunicação de más notícias, apontaram a necessidade de contemplar a comunicação clínica na formação e avaliação das diferentes especialidades e a promoção da formação contínua nesta área. Adicionalmente, referiram a estruturação longitudinal [34] e mais atenção da componente prática como aspetos fundamentais para a melhoria da formação pré-graduada. Na literatura há referência a vários modelos de formação para estudantes e internos de especialidade, que apresentam prós e contras [35]. Um exemplo dum modelo longitudinal ao longo de todo o curso de medicina descrito detalhadamente é o da Universidade de Ghent. Este programa integra vários métodos de aprendizagem como a observação de vídeos de entrevistas clínicas ou leitura de casos clínicos, o treino de competências em pequenos grupos (10-15 alunos) por role-playing com os colegas do grupo ou doentes simulados e no final observação de gravações de consultas reais desenvolvidas pelo estudante [36]. O modelo de ensino em ambiente clínico real através da observação e feedback destacado pelos participantes neste estudo no contexto real do do- 
ente, tem inerentes limitações da privacidade e restrição de tempo [35]. Trabalhos futuros de investigação multi-institucional poderão vir clarificar que modelo de ensino utilizar, quando iniciar a formação nesta área [8], como mensurar os efeitos dos programas de formação e qual o impacto que estes têm na prática clínica nas capacidades de comunicação [7].

No que concerne às limitações apresentadas por este estudo, estas prendem-se com a metodologia baseada em dois grupos focais selecionados numa instituição portuguesa, o que condiciona a generalização das suas conclusões. A clarificação a esse respeito requer a replicação da metodologia em mais contextos -por exemplo outras instituições hospitalares ou de cuidados primários-. Apesar da sua natureza exploratória, o estudo caracterizou com profundidade a experiência dos internos do ano comum relativamente à comunicação de más notícias e identificou um conjunto de fatores que poderão orientar a construção dum questionário que permita uma amostragem representativa das perceções dos internos em Portugal.

Em conclusão, os aspetos mais prementes identificados neste estudo na comunicação de más notícias de jovens médicos, foram as dificuldades de lidar com as emoções e com várias especificidades da prática clínica para as quais não tinham tido, nem viriam a ter formação estruturada e prática. Verificando-se em futuros trabalhos que estes aspetos são comuns à população em causa, é necessário sensibilizar as instituições para a importância da inclusão das competências de comunicação nos manuais de boas práticas. Parece ser também importante refletir sobre a estrutura curricular e sobre as metodologias da formação dos estudantes de medicina em comunicação clínica, com especial destaque na área das más notícias.

\section{Bibliografía}

1. Epstein RM Jr. Patient-centered communication in cancer care: promoting healing and reducing suffering. Bethesda, MD: National Cancer Institute; 2007.

2. Ong LM, De Haes JC, Hoos AM, Lammes FB. Doctor-patient communication: a review of the literature. Soc Sci Med 1995; 40: 903-18.

3. Stewart MA. Effective physician-patient communication and health outcomes: a review. CMAJ 1995; 152: 1423-33.

4. Aspegren K. BEME Guide no. 2. Teaching and learning communication skills in medicine -a review with quality grading of articles. Med Teach 1999; 21: 563-70.

5. Henry SG, Holmboe ES, Frankel RM. Evidence-based competencies for improving communication skills in graduate medical education: a review with suggestions for implementation. Med Teach 2013; 35: 395-403.

6. Arnold SJ, Koczwara B. Breaking bad news: learning through experience. J Clin Oncol 2006; 24: 5098-100.

7. Hulsman RL, Visser A. Seven challenges in communication training: learning from research. Patient Educ Couns 2013; 90: $145-6$.

8. Van Weel-Baumgarten EM, Brouwers M, Grosfeld F, Hermus FJ, Van Dalen J, Bonke B. Teaching and training in breaking bad news at the Dutch medical schools: a comparison. Med Teach 2012; 34: 373-81.

9. Ptacek J, McIntosh E. Physician challenges in communicating bad news. J Behav Med 2009; 32: 380-7.

10. Dosanjh S, Barnes J, Bhandari M. Barriers to breaking bad news among medical and surgical residents. Med Educ 2001; 35: 197-205.

11. Minichiello TA, Ling D, Ucci DK. Breaking bad news: a practical approach for the hospitalist. J Hosp Med 2007; 2: 415-21.

12. Quill TE, Townsend P. Bad news: delivery, dialogue, and dilemmas. Arch Intern Med 1991; 151: 463-8.

13. Dias L, Chabner BA, Lynch TJ Jr, Penson RT. Breaking bad news: a patient's perspective. Oncologist 2003; 8: 587-96.

14. Wall D, Bolshaw A, Carolan J. From undergraduate medical education to pre-registration house officer year: how prepared are students? Med Teach 2006; 28: 435-9.

15. Illing JC, Morrow GM, Rothwell nee Kergon CR, Burford BC, Baldauf BK, Davies CL, et al. Perceptions of UK medical graduates' preparedness for practice: a multi-centre qualitative study reflecting the importance of learning on the job. BMC Med Educ 2013; 13: 34.

16. Lasmarías C, Espinosa J, Martínez-Muñoz M, Bullich I, Alburquerque E, Gómez-Batiste X. Estudio sobre necesidades formativas en cuidados paliativos para atención primaria. FEM 2013; 16: 159-65.

17. Kitzinger J. Qualitative research. Introducing focus groups. BMJ 1995; 311: 299-302.

18. Presidência do Conselho de Ministros - Centro Jurídico. Portaria n. ${ }^{\circ}$ 251/2011 de 24 de Junho. Diário da República electrónico: Imprensa Nacional Casa da Moeda; 2011.

19. Patton MQ. Qualitative research and evaluation methods. 3 ed. California: Sage Publications; 2002.

20. Glaser B, Strauss A. The discovery of grounded theory. Chicago: Aldine; 1967.

21. Glaser B. Theoretical sensitivity. Mill Valey: Sociology Press; 1976.

22. Strauss A. Qualitative analysis for the social sciences. Cambridge, UK: Oxford University Press; 1988.

23. Brown R, Dunn S, Byrnes K, Morris R, Heinrich P, Shaw J. Doctors' stress responses and poor communication performance in simulated bad-news consultations. Acad Med 2009; 84: 1595-602.

24. Orlander JD, Graeme Fincke B, Hermanns D, Johnson GA. Medical residents' first clearly remembered experiences of giving bad news. J Gen Intern Med 2002; 17: 825-40.

25. Tulsky JA, Chesney MA, Lo B. See one, do one, teach one? House staff experience discussing do-not-resuscitate orders. Arch Intern Med 1996; 156: 1285-9.

26. Barnett MM, Fisher JD, Cooke H, James PR, Dale J. Breaking bad news: consultants' experience, previous education and views on educational format and timing. Med Educ 2007; 41: 947-56.

27. Veldhuijzen W, Mogendorff K, Ram P, Van der Weijden T, Elwyn G, Van der Vleuten C. How doctors move from generic goals to specific communicative behavior in real practice consultations. Patient Educ Couns 2013; 90: 170-6.

28. Rossi-Ferrario S, Cremona G. Communication in a medical setting: can standards be improved? Multidiscip Respir Med 2013; 8: 1 .

29. Buckman R. Breaking bad news: why is it still so difficult? Br Med J (Clin Res Ed) 1984; 288: 1597-9.

30. Baile WF, Buckman R, Lenzi R, Glober G, Beale EA, Kudelka AP. SPIKES -a six-step protocol for delivering bad news: application to the patient with cancer. Oncologist 2000; 5: 302-11.

31. Cardoso RM. Comunicar más notícias. Unidade de Psicologia Médica, Departamento de Neurociências Clínicas e Saúde Mental, Faculdade de Medicina da Universidade do Porto, ed. Portugal: Fundação Calouste Gulbenkian; 2012. p. 212-33. 
32. Espinosa E, González-Barón M, Zamora P, Ordóñez A, Arranz P. Doctors also suffer when giving bad news to cancer patients. Support Care Cancer 1996; 4: 61-3.

33. Bleakley A, Brennan N. Does undergraduate curriculum design make a difference to readiness to practice as a junior doctor? Med Teach 2011; 33: 459-67.

34. Van Dalen J, Kerkhofs E, Van Knippenberg-Van den Berg BW, Van den Hout HA, Scherpbier AJ, Van der Vleuten CP.

Longitudinal and concentrated communication skills programmes: two Dutch medical schools compared. Adv Health Sci Educ Theory Pract 2002; 7: 29-40.

35. Rosenbaum ME, Ferguson KJ, Lobas JG. Teaching medical students and residents skills for delivering bad news: a review of strategies. Acad Med 2004; 79: 107-7.

36. Deveugele M, Derese A, De Maesschalck S, Willems S

Van Driel M, De Maeseneer J. Teaching communication skills to medical students, a challenge in the curriculum? Patient Educ Couns 2005; 58: 265-70.

\section{Comunicación de malas noticias por los residentes de primer año: estudio exploratorio}

Introducción. La comprensión de las dificultades en la comunicación de malas noticias de los médicos recién graduados es importante para guiar el desarrollo de la educación de pregrado en esta área de la comunicación médico-paciente.

Objetivo. Explorar las percepciones de los médicos graduados en el final de su primer año de residencia, en relación con su preparación para dar malas noticias, y las características deseables de los planes de estudios médicos de pregrado eficaces en este ámbito.

Sujetos y métodos. Se realizó un estudio exploratorio cualitativo con dos grupos de enfoque de residentes de primer año ( $n=6$ y $n=7$ ) de un hospital en Portugal. Las sesiones de grupos focales fueron audiograbadas, transcritas y sometidas a análisis temático.

Resultados. Los residentes informaron de dificultades e inseguridad en la comunicación de malas noticias, aunque consideraran que tenían buenas habilidades de comunicación en general. Sus principales dificultades se centraron en afrontar las emociones y reacciones del médico y el paciente, como el llanto y el silencio. Experiencias negativas anteriores condicionaron su seguridad en la comunicación de malas noticias. Las principales limitaciones reconocidas en su formación de pregrado en esta área fueron la educación temprana y desarticulada en los planes de estudios y la falta de formación práctica.

Conclusión. La mejora de la formación médica de pregrado en malas noticias debe prestar atención a los aspectos emocionales del proceso. Debe diseñarse longitudinalmente, incluyendo la simulación y contextos reales.

Palabras clave. Comunicación clínica. Comunicación de malas noticias. Habilidades clínicas. Internado y residencia. Relación médico-paciente. Revelación de la verdad. 